\title{
Innovative Technology in Terms of Socio-Economic Value Diffusion: Accounting and Analytical Support
}

\author{
By Viktoriia Druzhynina ${ }^{1}$, Ganna Likhonosova ${ }^{2}$, Galyna Lutsenko ${ }^{3}$, Iryna Kushal ${ }^{4}$
}

\begin{abstract}
The potential of using information technology for socio-economic development of the country and the life quality of every citizen is quite significant now in Ukraine. The aim of the article is to study the modern possibilities of using information technologies, namely, adaptations of accounting and analytical support in the conditions of diffusion of socio-economic values to increase the welfare of the population. The methods of divergence and convergence, rationality and irrationality were used in the work - to search for effective tools for regulating national and international financial relations in Ukraine in the context of the challenges of globalization; methods of analysis of cognitive data to determine the forms and directions of digital hygiene in Ukrainian society; conceptualization of consequences and the duality of assessing results - to illustrate the reflection of the current state of development of the analytical basis and levelling Ukraine's dependence on financial hedonism, which currently prevails in the world. Specific areas of application of innovative technologies are proposed, such as tourism services and hotel and restaurant business. Ensuring the competitiveness of national industries as a result of their use of innovative behaviour and the development of new technologies and the accumulation by economically active subjects of innovative knowledge and empirical skills ensures the introduction of new information technologies in various spheres of human life, with no exception of tourism and restaurant industry. The modern industry of restaurant and tourism business has been actively using specialized software and global computer networks in recent years to increase the efficiency of the placement and search of information, the activation of promotion and services marketing, and the improvement of the quality of customer service, as this is an important condition for the quality of such services. Thus, integration aspirations in the global socioeconomic system should be supplemented by facilitating access to advanced information technologies within the country itself. This is a necessary condition for the process of diffusion of socio-economic development and innovative knowledge that should be accumulated in the country.
\end{abstract}

Keywords: innovation, technology transfer, welfare, socio-economic development, accounting and analytical support

\section{Introduction}

In the conditions of a dynamically developing market, innovations are a strategic factor in the success of any business entity, its universal competitive advantage, which ensures competitiveness in all market segments. In the difficult economic conditions for the functioning of enterprises, the basis of which was the influence of the consequences of the global pandemic COVID-2019 and the growing financial crisis, a tendency to increase the innovative activity of entrepreneurs begins to appear. Comprehensive

\footnotetext{
| ${ }^{1}$ Business Administration, Marketing and Tourism Department, Kremenchuk Mykhailo Ostrohradskyi National University, Kremenchuk, Ukraine

2Finance Department, National Aerospace University "Kharkiv Aviation Institute", Kharkiv, Ukraine

${ }^{3}$ Cyclic commission of general economic disciplines, Kremenchuk Flight College National Aviation

University, Kremenchuk, Ukraine

${ }^{4}$ Accounting and Taxation Department, Volodymyr Dahl East Ukrainian National University, Severodonetsk, Ukraine
} 
support for the management of innovation includes legal, regulatory, methodological, financial, material, personnel and information subsystems. The most important in the system of information support of innovation management is accounting and analytical information.

The implementation of innovation involves the receipt of income from innovation, which requires the creation of a certain innovative environment and technological management of it. At the same time, this is a type of activity taking place under conditions of uncertainty and a high level of risk, when the consequences of decisions are ambiguous and difficult to predict, which leads to increased requirements for the management system. Moreover, in market conditions with the expansion of economic independence of enterprises, the responsibility of managers for the correctness and validity of management decisions made by them increases.

The studies made it possible to establish that the current accounting and analysis systems do not fully meet the increased requirements for providing information to managers of various levels of management, which significantly reduces their value and effectiveness. Thus, at present, an objective need has arisen for improving the accounting and analytical system for managing innovative activities of organizations, which allows the generation and use of information on the stages of innovative activities in order to quickly respond to changing conditions of the innovative environment and the results of innovative activities.

Modern economic integration in the world is manifested in accelerating and expanding trade flows, capital flows, migration processes, which lead to higher living standards, poverty reduction, education, and health care.

The development of integration tendencies to date is due to a number of objective reasons: the need for socio-economic development in the country on the basis of division of labor and comprehensive specialization; accumulated professional and scientific contacts; Proven channels of international cooperation.

However, such socio-economic achievements are accompanied by negative consequences, such as the creation of political confrontations, provoking international conflicts and the emergence of military aggression. And these phenomena are accompanied by modern integration processes in Ukraine. Therefore, there is a need to indicate the direction of eliminating such negative phenomena, in particular unemployment, which is spreading in the world and in Ukraine. At the same time, employers are signaling the need for job placement for new employees, either insufficient in the labor market or absent at all. This phenomenon is explained by the fact that, on the one hand, there is a mismatch between demand and supply for specific types of work; on the other hand, lack of competence and professional experience of graduates and potential employees. For an employer, adapting a new employee to a position is usually an investment, which, for example, does not make sense in high un-employment. The most important fact is the placement of a competent employee. One of the main reasons for this is the fact that the labor market resources do not have time to absorb the knowledge, skills and competencies necessary for the intro-duction of new technologies into the production process of material products and services.

If we consider tourist services, which formally do not create an industry, but organize, in the process of their production it is difficult to calculate the number of eco-nomic 
entities. However, among them there are organizers of tourism, hotels, boarding houses, restaurants, managers and others. The development of the tourist services market is stimulated by three main trends: growing popularity and prospects; the opening of new important tourist attractions in different parts of the world; increase of significance of thematic tourism.

The first trend is obviously focused on new technologies of electronic communications. The second and third trends do not point to such an orientation. Few potential clients of tourist services can afford cognitive tourism. In holy with this, the most favorable form of tourism will be virtual tourism, which requires the use of information technology, experts in the field of e-tourism, which includes communication with the client, travel planning and its implementation in the virtual world.

\section{Literature Review}

The world has accumulated considerable experience and diversity of forms of international economic cooperation focused on integration tendencies. Questions of the relationship between economic integration and the dynamics of potential expansion are discussed in the context of the integration of financial markets and the growth of industrial specialization (Bommier, A., Bretschger, L., Le Grand 2017). D. Brou and M. Ruth have built a model that shows that in cases where economic integration is accompanied by cooperation at the political level, it intensifies innovation activity, as firms in such conditions face less rigorous competition (Brou \& Ruta, 2011). By analyzing the relationship between economic integration, product and process innovations and the comparative demand for competence through the prism of the model of international oligopoly, S. Braun has confirmed that a reduction in competition raises the demand for skilled labor (Braun, 2008). However, almost twenty years ago, the threat of lack of a forecast of the consequences of the integration of economic and social policies in the long run, which could lead to a reduction in the country's scientific and technological potential, was characterized. This is due to the slowdown in the rate of innovation development and economic growth due to the large-scale shift of resources from the fundamental ones (giving the effect more quickly in the long run) to applied research, which can quickly affect the competitiveness and, accordingly, the potential of the country (Xie, 1999).

Therefore, the potential of using information technologies for socio-economic development of the country and the quality of life of each citizen (Druzhynina, 2013), which will be based on better access to resources, raw materials, commodity markets and financial capital, is quite significant now in Ukraine.

Through the efforts of scientists, the conceptual apparatus and the main economic mechanisms for managing innovative processes of the organization (Gudzinsky, 2008), as well as certain aspects of tracking trends in socio-economic transformations (Calinescu, 2018a) have been developed. The developments of these authors are undoubtedly of great theoretical and practical importance. A study of most of the works devoted to innovative technologies and analytical bases in the economy revealed that, despite the existence of an extensive theoretical base, the conceptual and methodological foundations of accounting and analysis in a complex system of diffusion of social and 
economic values of society have not been developed. The objects of accounting and analysis in this area are not clearly defined, there is no methodology for their phased accounting and analysis, the possibilities of using modern concepts and methods of special types of accounting, technologies and economic analysis in the field of social application, in particular in tourism, have not been sufficiently studied. The lack of a comprehensive and systematic approach to this issue, in our opinion, is associated with the scale of the content of social and economic values, as well as the multidimensionality and multivariance of the socio-economic system. In addition, the active development of accounting and analysis systems, the emergence of improved concepts and methods require their adaptation to the processes of socio-economic development.

Recently some aspects of innovative development of tourism, restaurant industry and evaluation of the effectiveness of innovation policy of enterprises of this type of activity were covered in the works of G. Pyatnitskaya, O. Grigorenko, O. Borisova. But with all the multifaceted research, the processes of using information technology in various spheres of human life support continue to attract the attention of different researchers, which explains the relevance of the topic and the need for its further scientific substantiation.

\section{Research Methodology}

Highlighting outstanding issues as a part of generic problem of the paper. The progress makes a danger in which people being performing rote job will be replaced by mechanisms and machines, but the most innovative enterprisers have a plan to enlarge the amount of workplaces. The exposure the modern context and role of innovative activity in a process of formation, regulation and effective realization of labor policy actualized the selection of research direction.

The aim of the article is to study the modern possibilities of using information technologies, namely, adaptations of accounting and analytical support in the conditions of diffusion of socio-economic values to increase the welfare of the population. Specific areas of application of innovative technologies are proposed, such as tourism services and hotel and restaurant business.

Conclusions, suggestions and recommendations made in the study are reasonably substantiated from a theoretical and practical point of view and are based on the scientific research methodology, the use of scientific data systematization techniques: the dialectical approach, induction and deduction methods, analysis and synthesis, groupings, expert estimates, optimization, abstract logical, balance, calculation and variation methods, individual techniques of applied statistical and econometric analysis, economic and mathematical modeling, forecasting.

\section{Research Results and Discussion}

In the theory and practice of integration processes, two types of economic integration can be distinguished. One of them is the formation of the principles of the global economy. This type of economic integration involves the formation of a new economic structure and is based on the development of transnational economic structures. 
The main feature of economic integration is the emergence of powerful eco-nomic and other types of blocs, such as the EU, NATO, etc. Another type is the preservation of independent national economies, which are developing at the expense of the growth of domestic business entities and the use of internal resources. The entry of cranes into international processes takes place with the preservation of national economic independence.

Intensification of international cooperation can provide new opportunities for accelerating socio-economic development at certain levels (Figure 1).

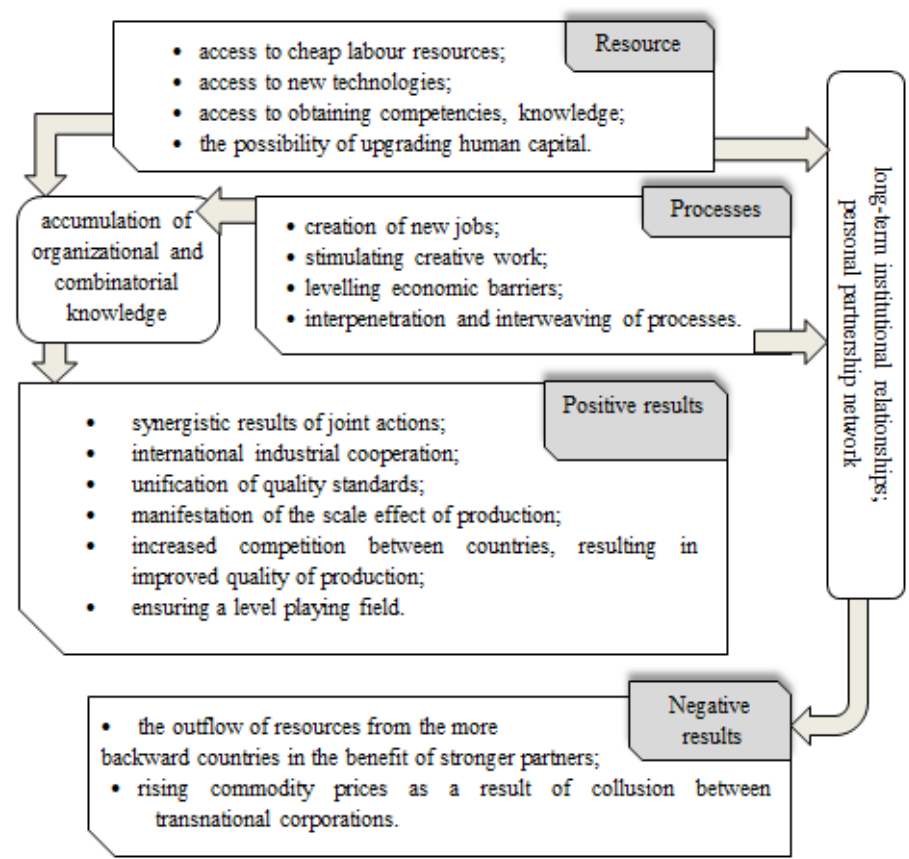

Figure 1: Levels of use of information technology based on integration trends

Source: created by the authors

Among the main positive trends in the integration processes in the field of socioeconomic potential formation (Calinescu et al, 2018b), the country can be distinguished: ensuring the competitiveness of national industries as a result of their use of innovative behavior and the development of new technologies and the accumulation of innovative knowledge and empirical skills by economically active subjects.

Along with the problems of integration transformations of Ukrainian society, let us single out another problem of promoting innovative technologies at Ukrainian enterprises. This problem is often associated with the reluctance of Ukrainian business to introduce management accounting systems. This is often explained by the fact that the mechanisms for introducing the achievements of scientific and technological progress, taking into account the innovations of enterprises with various innovative strategies are still not sufficiently implemented in Ukrainian legislation.

In management accounting of innovative support, the enterprise management should 
concentrate on the proposed factors and accounting objects (Figure 2). The presentation of costs by factors having direct and indirect financial estimates allows us to develop measures for managing factors and to distribute responsibility for the high-quality implementation of these measures.

As Basova determines (Basova 2016), factors that have a direct financial assessment are controlled by a system of measures within the framework of a particular business process. Factors having an indirect financial assessment are managed with great uncertainty and a high risk of failure. Actions to manage such factors are carried out in the framework of various business processes, and these activities are not directly related to the impact on this particular factor.

A financial assessment of the impact of income and expense factors captures the level of manageability achieved and contributes to the adoption of effective management decisions. Such an assessment is provided by the budgeting process of innovations introduced by the enterprise.

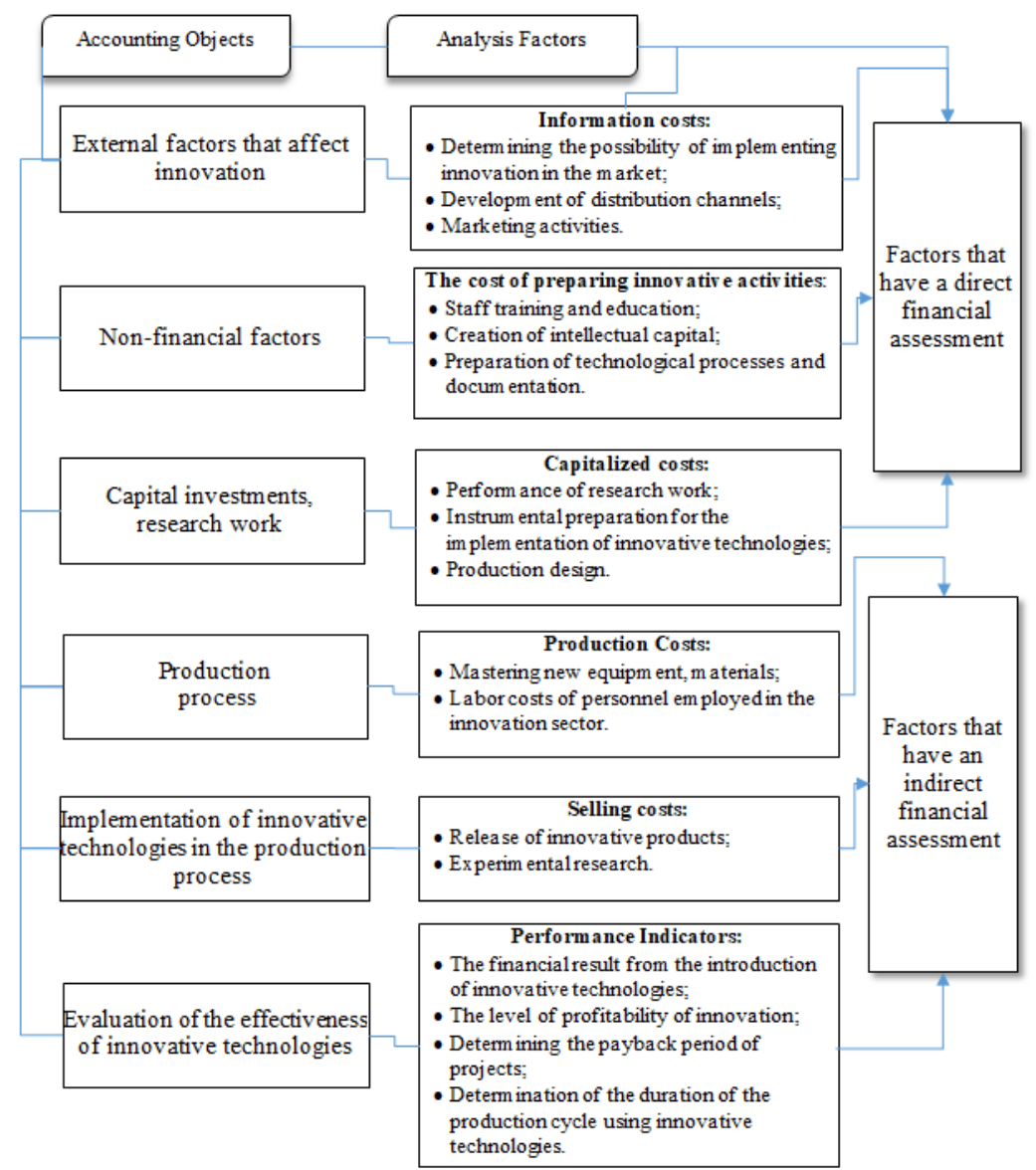

Figure: 2 Classification of objects and factors of the accounting and analytical basis for the implementation of innovative technologies

Source: created by the authors 
The general market provides opportunities not only for acquisition of a greater spectrum of new production technologies and equipment, but also the training of a large number of organizational innovations. With the intensification of interaction its participants learn faster (Pobol, 2012). The speed with which enterprises learn and accumulate the necessary resources determines their chances of penetration into the market, further growth and sustainability.

The modern industry of restaurant business and tourism has undergone very serious changes in recent years due to the introduction of new information technologies. Seeking to raise the prestige of their hotel or boarding house, to ensure the clarity and efficiency of customer service, to establish control over the actions of personnel, etc., the hotel leader inevitably comes to the idea of the need to purchase and further introduction of the automated system.

Successful operation of any company in the tourist business market is practically unthinkable without the use of modern information technologies. The specifics of technology for the development and marketing of tourism products require such systems that would provide information on the availability of vehicles and facilities for tourists at the earliest possible time, provide for quick reservation and reservation of seats, as well as automating the solution of auxiliary tasks in the provision of tourist services (parallel processing of such documents, such as tickets, accounts and guides, providing settlement and background information, etc.). This can be achieved with the wide use of modern computer technology for the processing and transmission of information.

The tourism industry is so diverse and multifaceted that it requires the use of a wide variety of information technologies, from the development of specialized soft-ware that automates the work of a particular tourist firm or hotel, to the use of global computer networks.

Today, one of the most common types of information technology is the Internet, which enables communication and communication between users around the world. Nowadays, more and more tourists are beginning to use the possibilities of the Internet, namely: receiving information about countries, operational weather forecast in different countries of the world; Get information on rates and prices in hotels, restaurants and other travel services; independent formation of the tour and the purchase of a tourist tour.

An important role is played by information technology in the implementation of marketing functions, because it is the coordination of marketing efforts, the development of programs of tours, as well as pricing influence the improvement of the tourism product, because with the help of marketing, it is possible to promote the tourism product to the market of travel services (for example, the promotion of hotels in Ukraine to the world market may be the marketing company "Top Ukrainian Hotels", organized by the travel company "Arcturus").

In developing the program of the tour takes into account many factors (travel route, a list of travel companies-partners, the period of service of each enterprise - the provider of services, the list and composition of services provided during the tour, a range of entertainment activities and animation programs, the time of stay of tourists at each point of the route etc.), so it is a rather complicated process, and the solution to this problem has become possible thanks to information retrieval systems designed for both tourists and professionals in the tourist business. These systems allow for advanced search and booking of tours in-line, as well as search of the electronic atlas of the world, 
dynamic market tables, etc. The most common systems, their ad-vantages and disadvantages are shown in Table 1.

World experience shows that for any travel agency a factor determining the success of its activities in the tourist market is the time of customer service. The winner is the one who has the opportunity to provide the client with a full range of services on-line.

An important impetus for the development of the tourism industry and the promotion of the tourism product to the world market is communication policy and e-business, consisting in the use of information technologies for the implementation of the tourist product, primarily through Internet advertising, as well as the implementation of basic business processes using informational and telecommunication technologies.

Tourist Internet portal - a large site that offers visitor various services in the field of tourism. Internet portals are distributed among many large enterprises and have their advantage primarily in: opportunities for prompt placement and information retrieval; large-scale, round-the-clock, efficient and very cheap advertising; saving money when using e-mail in the process of interaction with foreign and domestic partners; the ability to receive new information on tours and discounts in a timely manner.

\section{Table 1. Global Distribution Travel Systems}

\begin{tabular}{|c|c|c|c|c|}
\hline \multirow[t]{2}{*}{ Indexes } & \multicolumn{4}{|l|}{ Systems } \\
\hline & Sabre & AMADEUS & Galileo & Worldspan \\
\hline $\begin{array}{l}\text { Quantity } \\
\text { of employees }\end{array}$ & 9000 & 3654 & No data available & 3200 \\
\hline Distribution & $\begin{array}{l}\text { More than } 59,000 \\
\text { travel agencies }\end{array}$ & $\begin{array}{l}54405 \text { travel } \\
\text { agencies in } 198 \\
\text { countries }\end{array}$ & $\begin{array}{l}\text { More than } 52,000 \text { travel } \\
\text { agencies in } 116 \text { countries }\end{array}$ & $\begin{array}{l}20210 \text { travel agencies } \\
\text { in } 60 \text { countries }\end{array}$ \\
\hline Revenues & $\begin{array}{l}\text { 2,5 billion US } \\
\text { dollars }\end{array}$ & 1,6 billion euro & 1,6 billion US dollars & No data available \\
\hline $\begin{array}{l}\text { Number of } \\
\text { bookings }\end{array}$ & 467,1 million & 393,9 million & 345,1 million. & No data available \\
\hline Suppliers & $\begin{array}{l}450 \text { airlines } \\
53000 \text { hotels } \\
54 \text { car rental } \\
\text { companies }\end{array}$ & $\begin{array}{l}480 \text { airlines } \\
54641 \text { hotels } \\
47 \text { car rental } \\
\text { companies }\end{array}$ & $\begin{array}{l}425 \text { airlines } \\
60,000 \text { hotels } \\
23 \text { car rental companies } \\
430 \text { tour operators }\end{array}$ & $\begin{array}{l}533 \text { airlines } \\
47000 \text { hotels } \\
45 \text { car rental } \\
\text { companies }\end{array}$ \\
\hline Advantages & $\begin{array}{l}\text { Simplified search } \\
\text { for low flight } \\
\text { prices; } \\
\text { Introduction of a } \\
\text { new program on } \\
\text { reservation of } \\
\text { places on railways, } \\
\text { buses and } \\
\text { passenger ships }\end{array}$ & $\begin{array}{l}\text { Actively enters the } \\
\text { Ukrainian market } \\
\text { of tourist services; } \\
\text { Provides data } \\
\text { storage, } \\
\text { calculation and } \\
\text { payment } \\
\text { collection for all } \\
\text { types of services; } \\
\text { Provides } \\
\text { management of } \\
\text { commission fees } \\
\text { when booking } \\
\text { hotel rooms }\end{array}$ & $\begin{array}{l}\text { Provides access to the tour } \\
\text { operator's database and } \\
\text { provides agencies with the } \\
\text { opportunity to search and } \\
\text { book hotels, villas, } \\
\text { apartments, tours, } \\
\text { excursions, organization of } \\
\text { transfers in } 112 \text { countries of } \\
\text { the world. }\end{array}$ & $\begin{array}{l}\text { The reservation is } \\
\text { carried out mainly on } \\
\text { air transport, } \\
\text { theaters, excursion } \\
\text { bureaux, cultural } \\
\text { enterprises; } \\
\text { Provides background } \\
\text { information related } \\
\text { to tourism; } \\
\text { The client can } \\
\text { independently } \\
\text { choose the flight, } \\
\text { hotel and make their } \\
\text { booking }\end{array}$ \\
\hline
\end{tabular}

Disadvantages 1.Most of travel agencies provide incomplete information to customers on sites about hotels or boarding houses, and information about the cost of services is often outdated and inaccurate. 


\begin{abstract}
2. Insufficient staff qualification. The vast majority of tourism workers have a humanitarian background, which causes some difficulties in working with computers and the Internet. Training of employees or recruiting professionals requires additional funding.

3. Lacks in the reservation system of hotel rooms.

The distribution was maintained by a reservation system, when the tourist is renting a hotel room according to the price, but does not know the name of this hotel until its arrival. This system is called in different operators in different ways: ROULETTE, TEZ-EXPRESS. Many operators prefer such a system because it allows you to save a budget for a trip and stay in a good hotel, but often the result does not justify the tourist's expectations.
\end{abstract}

Source: Official web-side of State Statistics Service of Ukraine, 2020

But it should be noted that by creating its own travel portal on the Internet, it is necessary to pay attention first of all to the requests of tourists, to provide this information on their site and to monitor its constant updating.

In addition to the tourist portal, the following Internet technologies should be noted: Street View, Google Earth, Google Art Project, multimedia presentations - high-quality spherical panoramas (virtual tours); mobile apps: Google Googles, 3D guides, travel interpreters, Word Traveler, etc .; complementary reality programs. The Inter-net has become a new generation, digital generation, the main source of tourist in-formation. The tourist facility has its own website, but also the fact that the internet community does this to check this information through online forums, publishing their photos. We also have a digital image at our disposal around the world, and the undoubtedly leader is Google Inc., which offers two of the most famous product - Google Maps and Google Earth. It is important that the software for home use be in the free version. These addons, in addition to satellite images, are enriched with amateur photographs, as well as through webcams with online images. Thus, before leaving, the tourist can assess whether the proposal presented in the travel company is true. Most young tourists are preparing for a trip using Internet locators.

When traveling by car, more and more people are using GPS receivers. Only 4-5 years ago they were used very little. The development of the market for GPS receivers can be compared with the expansion of mobile phones in recent years. Almost all new cars are equipped with GPS receivers. More and more new mobile phones also have a built-in GPS receiver. Another trend is to connect a GPS receiver to an iPad or a smartphone. Thus, the function of individual devices is blurred, and we get a multi-function device that plays the role of computer, phone, camera and location device.

There are also new types of GPS receivers called data loggers that are useful for walking and cycling. Holux advertises them as devices that can be used during everyday trips and trips to rest, as well as in transport, tourism, agriculture and forestry. These receivers not only inform about the current geographic location, but also record the route passed by the user. For example, the Holux M-241 receiver, equipped with an LED display, allows you to read geographic location information. The receiver has a built-in Bluetooth module that provides wireless connectivity to a computer or mobile phone. The receiver weighs only $39 \mathrm{~g}$, and the battery lasts 12 hours. Comfortable work is additionally provided with small receiver sizes and low energy consumption from AA batteries. For cycling, it is recommended to use the Holux GR-245 receiver, which is easily mounted on the steering wheel. These receivers are equipped with software that allows you to 
synchronize your travel pictures, history, and transfer them to a map using Google Earth. The latter version was very well received by young people enthusiastic about digital photography. Google allows you to create presentations from your own photo albums. You can not only use the Piacasa Web Album app and view your photo collections, but first of all post your own. Thus, a creative approach to sightseeing is encouraged. The next step, which allows travelers to realism - the creation of threedimensional object models based on their own photos. This is a Photosynth service from Microsoft. This system compares the position and proportions of objects in different images and finds common points (creates from the photos the so-called cloud of points). Then he applies the images to a three-dimensional model generated in this way.

The general recognition of mobile phones creates the possibility of wider use of these devices, especially for obtaining information from the Internet. The mobile version of the Zumi site exists throughout the year under the name of ZumiLajt, which contains all the important functions of the original. In addition, one click can be contacted by phone from a company found (hotel, restaurant, etc.). There are also mobile sites for hosting. Cities have their own sites that facilitate travel not only for tourists, but also for employees who come for professional purposes.

One of the most profitable and promising sectors of the world economy is the modern hospitality industry, the most important part of which is the restaurant business. Nowadays, it remains one of the most widespread types of small businesses, so institutions are constantly fighting among themselves for segmentation of the market, for finding new ones and for maintaining the regular consumers of their products and services. The restaurant business is the main factor and the main component of the tourism infrastructure, plays a leading role in the presentation of the domestic tourist product in the world market of tourist services. This sphere of tourist services of the world economy is developing rapidly and in the long term may become the most important sector of tourist activity.

Every year in Ukraine, the number of restaurants is increasing. This is primarily due to the growing need for food for people and leisure. In order to keep regular visitors and attract new ones in a competitive environment, stylish interiors and quality tasty food are no longer enough. Innovations in the restaurant business come here for help - interesting marketing steps, for which the customers want to come to this restaurant again.

Modern restaurant customer - a person who lives in a digital age and actively uses various gadgets. Therefore, the introduction of new technologies into the restaurant business becomes a vital necessity. The transition to digital technology may initially seem rather costly, but if this step is considered as a necessary investment, act systematically and according to the plan, then investments will quickly generate profits.

At present, a large number of different catering establishments are represented in the market of restaurant services: they are institutions of various styles and concepts. Such a large number of offers in the market leads to increased competition. As a rule, enterprises that strive to continuously improve their activity, using different innovative approaches, are usually in the most winning position, add to the institution the uniqueness, originality, the ability to meet changing consumer demands and requirements.

The convenience of automation and informatization of processes at the catering 
company is evident not only from the point of view of "doing business", but also from the standpoint of clients, since information systems allow more efficiently to make calculations with visitors, the order of service, the provision of the proposed menu with all the necessary ingredients.

Technologies are developing and implemented rapidly. This is connected not only with the relief and improvement of the work of restaurant staff, as well as with the involvement of as many clients as possible, arranging all the necessary conditions and making the customer a permanent guest.

Taking into account the above it is possible to explore innovations in the restaurant business. IT technology: Wi-Fi (Wireless Fidelity) - is a modern technology of wireless access to the Internet. Access to the network using Wi-Fi technology is done using special access radios. You can connect to a Wi-Fi network using laptops and mobile devices equipped with special equipment. One of the main advantages of any Wi-Fi network is the ability to access the Internet for all its users. The disadvantages of introducing such innovation include the particular sensitivity to electromagnetic radiation produced by household appliances. Despite world standardization, many devices from different manufacturers have incomplete compatibility with each other.

Electronic menu (iPad) - an interactive e-menu as a communication channel be-tween restaurant and visitors, which allowed the administration to quickly edit lists and add new dishes to it. The advantage of such technology is that it allows you to select wines from the wine list of the restaurant for the price, year, region, bouquet, and then to it - a dish from the local menu; calculate the caloric content of those or other dishes; at the choice of dishes immediately see the final order check; waiting for an order to play games, read news, wander around the Internet. But in this kind of positivity, guests are forced to place themselves closer to the terminal in turn, the terminal usually selects one seat near the table, it is extremely uncomfortable for the waiter to make an addition to the order at such a terminal, and finally the equipment of each table requires a large amount of costs for this terminal, which determines the negative moments of use such information technology.

The QR code is a matrix code that can hold a huge amount of information in the form of text, numbers, URLs, calendars, charts, and images. The speed of QR code recognition is very high, it can be placed on any media, starting with cash checks and menus and ending with different signboards and even stretch marks. It can be scanned either by a mobile phone or a laptop video camera. In the code you can encode the history of the restaurant, origin, age, authorship of the unique details of the interior and paintings; thanks to the information posted on the QR code about the time of work of the institution and contacts, the number of orders for offices and home will be increased; using the QR-code, the restaurant can notify its clients about promotions, lotteries, drawings, activate all kinds of loyalty programs, organize voting, interactive polls and quickly get restaurant reviews from your customers. But not all techniques are suitable for scanning this code.

The warmth of innovation, the essence of which is due to the fact that next to the workplace of the cook in the kitchen set the camera, and on the monitor on the table for his actions are observed only those visitors who are interested. The consumer can see how the dishes are cooked in this institution. Not everybody wants to see the 
technological process of cooking and fulfilling sanitary and hygiene norms, which characterizes the prevailing lack of innovation.

The system of discounts - an integrated discount system allows you to introduce a flexible system of discounts for each consumer. The system of discounts as a kind of information technology is aimed at increasing demand; strengthening of the positive image of the restaurant business enterprise; increasing the effectiveness of advertising; getting social effect. But when it is used, the disadvantages are identified: the risk of loss of profit, additional costs for an advertising campaign, the possibility of creating a "deficit" of the product, the probability of occurrence of extraordinary situations.

Payment devices located near the tables allow you to pay by credit card without getting out of place, which definitely reduces payment time; increases the degree of customer satisfaction, but the equipment of each table by such a terminal requires a large amount of expenses.

Biometric information readers identify people based on their unique physical traits and store these identifiers for further verification of the same clients, such a system reduces transaction fraud, salary and price, which is an advantage, but violates the personal space of a person.

Innovative technologies are developing rapidly, conditions are created to facilitate and improve the service of the institution, as well as for the convenience of the consumer of these services, institutions of the restaurant industry as a whole are prone to a variety of innovative changes.

\section{Conclusions}

Summing up the research, we note that, firstly, economic development is a consequence of a certain socio-economic policy and the driving force of an integrated society, when public interests turn into public selfishness. Hence, then social virtues can be transformed into certain system negatives; Secondly, on the basis of the con-ducted research, it is possible to determine the main directions of increasing the efficiency of tourism in the use of information technologies: increasing the efficiency of placement and information search, activating promotion and marketing of tourist services, improving the quality of customer service, as this is an important condition for quality assurance tourist services; Thirdly, younger generation, especially students, use new information technology devices during their travels. This often occurs only during the planning stage, since some unnecessary devices interfere with the sensation of beauty. On the other hand, it is recommended to bring devices that pro-vide the highest level of security in emergencies (mobile phone, map and increasingly GPS receiver). Due to the fact that the mobile phone more and more often contains a GPS receiver, it is especially valuable that the operator can find lost or need help and provide this information to the emergency services. This function, although technically easy to implement, has been locked for a long time; Thirdly, in recent years, innovations have substantially changed the catering industry and tourism in general, which will enable tourists of different ages to travel both in reality and virtually, if for some reason, there are no real trips. Thus, integration aspirations in the global socio-economic system should be supplemented by facilitating access to advanced information technologies within the country itself. This is 
a necessary condition for the process of diffusion of socio-economic development and innovative knowledge that should be accumulated in the country.

\section{Author Contributions}

Conceptualization, V.D. and L.S.; validation, V.D. and L.S. and G.L.; studies of domestic and foreign scientists, held in conjunction with highlighting the issues, G.L, and I. K.; Development of an algorithm for the formation of a tourist tour taking into account many factors using information retrieval systems; identification of trends focused on new technologies of electronic communications, taking into account the economic opportunities of society, in particular regarding tourism services, V.D. and L. S.; written original training project V.D. and L.S.; writing-reviewing and editing, V.D. and L.S. and G. L.; managing the project, V. D.; formation of levels of use of information technology based on integration trends, G.L.; structuring the innovation market to acquire a wider range of new manufacturing technologies and equipment, as well as to train a large number of organizational innovations, G.L.

\section{Disclosure Statement}

All authors have no competing financial, professional or personal interests on the part of other parties.

\section{Reference}

Basova, A.V. (2016). Development of accounting and analytical support for innovative processes in the management accounting system. Investments. Building. Real Estate, 1(16), 11-20.

Bommier, A., Bretschger, L. and Le Grand, F. (2017). Existence of equilibria in exhaustible re-source markets with economies of scale and inventories. Economic Theory. Volume 63, Is-sue 3, pp 687721. doi.org/10.1007/s00199-016-0956-5

Braun, S. (2008). Economic Integration, Process and Product Innovation, and Relative Skill Demand. Review of International Economics. Vol. 16(5), 864-873.

Brou, D., Ruta, M. (2011). Economic integration, political integration or both? Journal of the European Economic Association. Vol. 9(6), 1143-1167.

Calinescu, T., Likhonosova, G. and Zelenko, O. (2018a). Estimation of conditions the realization of democratic mechanisms the transformation of society: tearing away and social dialog. Montenegrin Journal of Economics. Vol. 14, 1, 93-107.

Calinescu, T. Likhonosova, G. and Zelenko, O. (2018b). Mechanism of Transformation Socio-Economic Potential of Ukraine: Tearing Away and Social Dialogue. Proceeding of the 32nd International Business Information Management Association Conference (IBIMA), 15 - 16 November 2018, Seville Spain. Vision 2020: Sustainable Economic Development and Ap-plication of Innovation Management from Regional expansion to Global Growth. Editor Khalid S. Soliman. Seville Spain: Information Business Information Management Association (IBIMA) Copyright, 949-965.

Druzhynina, V. (2013). Formation principles for the mechanism of the local labour market balancing. Actual Problems of Economics, 4(142), 202-208.

Druzhynina, V., Davidyuk, L. and Lutsenko, G. (2019). Possibilities of information technologies in the field of tourism. Organizational-economic mechanism of management innovative development of economic entities: collective monograph / edited by M. Bezpartochnyi, in 3 Vol. / Higher School of Social and Economic. Przeworsk: WSSG. Vol. 2, 154-164. 
Fedulova, L. (2011). Cooperation of the Republic of Belarus and Ukraine in the sphere of providing innovative development of economy and new quality of economic growth. Eurasian Economic Integration, 2 (11), 51-70.

Golub, A. (2018). Where the compass points. What proportion of Ukrainians really know what NATO is and how their attitude differ from those of their EU neighbor. The Ukrainian week, 11(129), 12-13.

Gudzinsky, O., Kireitsev, G. and Pakhomova, T. (2008). Theoretical aspects of the formation of accounting and analytical management mechanism. Accounting and Finance of Agribusiness, 3, 89-93.

Innovations in the restaurant business. http://prohotelia.com.ua/2013/02/restaurant-innovation/ Accessed $2020 / 06 / 11$

Kramar, O. (2018). Breaking through the asphalt. What's happen with Ukraine's exports? The Ukrainian week, 6(124), 24-25.

Xie, X. (1999). Economic Integration and Economic Growth with Science-Pushed Industrial Innovation. Review of International Economics. Vol. 7, 613-624. 